\title{
Las Obras por Administración Directa y por encargo: ¿Solución o problema? ¿Hay que restringirlas $?^{(* *)\left({ }^{* * *}\right)}$
}

\section{Proyects by direct management and custom proyects: solution or problem? Should we restrict them?}

\begin{abstract}
Resumen: El autor realiza un análisis de la facultad que tienen, bajo ciertos supuestos, las entidades públicas para atender sus propias necesidades de bienes, servicios y obras sin necesidad de contratar con privados, sino recurriendo a la autoprovisión. El estudio realizado abarca las condiciones en las cuales las entidades pueden optar por esta alternativa, los límites que existen para ello y las consecuencias que traen para la eficacia de la gestión de la entidad. Además, el autor propone consideraciones que debería adoptar la legislación en la materia para un mayor control y verificación de las condiciones de eficacia.
\end{abstract}

Palabras Clave: Bienes - Servicios - Obras - Autoprovisión - Administración Directa - Recursos - Entidades

\begin{abstract}
The author performs an analysis of the power that public entities have, under certain assumptions, to attend their own needs for goods, services and proyects without the need of contracting with private individuals, but using self-provision. The study covers the conditions under which entities can opt for this alternative, the limits that exist for it and the consequences they bring to the effectiveness of the entity's management. In addition, the author proposes considerations that should be adopted by legislation in the field for greater control and verification of the conditions of effectiveness.
\end{abstract}

Keywords: Goods - Services - Proyects - Selfprovision - Direct Management - Resources - Entities

$\left(^{*}\right)$ Abogado por la Universidad San Martín de Porres. Magíster en Derecho Constitucional por la Pontificia Universidad Católica del Perú. Profesor de diversos cursos de derecho administrativo a nivel de pregrado y Maestrías en las Facultades de Derecho de la Pontificia Universidad Católica del Perú, de San Martin de Porres y la Universidad de Piura. Directivo de la Asociación Peruana de Derecho Administrativo. Miembro de la Asociación Peruana de Derecho Constitucional y de la Sociedad Peruana de Derecho de la Construcción. Miembro del Foro Iberoamericano de Derecho Administrativo y de la Asociación Internacional de Derecho Administrativo - AIDA (2016). Socio del Estudio Echecopar Asociado a Baker \& Mckenzie International. Correo electrónico: juancarlos.moron@bakermckenzie.com

${ }^{(* *}$ Ponencia presentada para el II Congreso Nacional de Derecho Municipal, Arequipa, Perú en noviembre de 2016.

$\left.{ }^{* \star *}\right)$ Nota del Editor: El artículo fue recibido el 15 de diciembre de 2016 y aprobada su publicación el 17 de diciembre del mismo año. 
Las Obras por Administración Directa y por encargo ¿Solución o problema? ¿Hay que restringirlas?

Proyects by direct management and custom proyects: solution or problem? Should we restrict them?

\section{Introducción}

La disyuntiva de las entidades públicas entre atender sus necesidades de bienes, servicios y obras mediante sus medios propios o proceder a su externalización, a través de acuerdos patrimoniales con empresas privadas, se encuentra en el centro del análisis de este tema. ¿Hasta qué punto?, ¿con qué presupuestos y requisitos?, ¿con qué limites las entidades pueden auto organizarse para atender sus propias necesidades de bienes, servicios u obras con sus exclusivos instrumentos, organismos, recursos y personal? $\mathrm{O}$, por el contrario, ¿cuándo debe buscar satisfacer estas necesidades acudiendo al mercado, creando relaciones jurídico-patrimoniales con proveedores privados?

Indudablemente, detrás de este tema encontramos dos concepciones diferentes y en controversia sobre lo que debe ser contemporáneamente la actuación económica de la administración, de la política pública y de la ideología política sobre los linderos de la gestión gubernamental. ¿En cuál de estos roles la iniciativa estatal cumple mejor su rol subsidiario establecido en el artículo 60 de la Constitución Política?(1)

Nos encontramos frente a la alternativa excluyente de aceptar la autoprovisión como la primera opción de cualquier gerente público, que podríamos sintetizar en la máxima "no contrates con una empresa lo que te pueda hacer una organización pública" (Amoedo 261)(2), priorizando con ello, una acción directa, inmediata y sin el costo adicional que representa la utilidad que el tercero traslada en el precio. En este marco, las entidades actúan mediante suministros domésticos o también denominada administración directa, cuando, cubren sus necesidades de servicios mediante su propio personal, o cuando en vez de contratar una obra con contratistas particulares, proceden a la autoconstrucción con sus servidores públicos, equipos, materiales y experiencia. Por otro lado, se encuentra el dogma liberal del "contratista interpuesto", por lo que se hace necesario contratar preferentemente con terceros privados cada vez que la administración tiene una necesidad de bienes, servicios u obras, atendiendo a razones de eficiencia, costos, no interferencia en los mercados por parte de la administración manteniendo un rol subsidiario, entre otros.

Al mismo tiempo, este tema nos propone una delimitación en negativo del límite subjetivo del ámbito de la contratación pública, pues dependiendo del alcance permitido a los aprovisionamientos mediante medios propios, el ámbito de la contratación con el mercado (alcance de la contratación pública) se extenderá o reducirá respectivamente (De la Cuadra 892).

Por toda esta relevancia es que consideramos de interés afrontar el análisis de lo que la doctrina reconoce como los suministros in house providing (suministro doméstico o interno), operaciones in house, contractsmaison o, simplemente, administración directa de actividades, reconociendo que nos encontramos frente a un asunto bastante polémico y en dinámica evolución en el ámbito internacional. Es importante no perder de vista que no estamos abordando un tema marginal, sino uno económicamente relevante para la ejecución financiera del Estado, dado que un dato no menor es que, por ejemplo, las obras realizadas por administración directa alcanzan una participación relevante en los gastos de presupuesto público del orden de alrededor del $30 \%$ de la ejecución anual(3).

(1) "Artículo $60^{\circ}$.- El Estado reconoce el pluralismo económico. La economía nacional se sustenta en la coexistencia de diversas formas de propiedad y de empresa".

(2) También de este mismo autor puede revisarse respecto de este tema sus trabajos: Amoedo Souto, Carlos. "El nuevo régimen jurídico de la encomienda de ejecución y su repercusión sobre la configuración de los entes instrumentales de las administraciones públicas", Revista de Administración Publica 170, (mayo-agosto 2006): 261 y siguientes; además Carlos Amoedo Souto, TRAGSA: Medios Propios de la Administración y Huida del derecho administrativo (Barcelona: Atelier, 2004).

(3) Conforme al Dictamen Congresal recaído en el Proyecto de Ley 2533/2013-CG que propone la Ley de ejecución de obras públicas por administración en el año 2011, alcanzó el $27 \%$ y el año 2012, el 31\% del presupuesto nacional. 
Juan Carlos Morón Urbina

\section{El concepto de auto provisión de bienes, servicios y obras y el argumento de la eficacia de la gestión}

La doctrina reconoce a las operaciones in house como "las prestaciones de servicios, suministros de bienes y ejecuciones de obras realizadas a una autoridad pública por sus propios servicios (in house en sentido estricto) o (por) entidades en relación de dependencia (cuasi internas o in house en sentido amplio)" (Pernas García 176) ${ }^{(4)}$.

En todos estos casos, la entidad emplea sus propios medios administrativos, recursos humanos y técnicos para aprovisionarse de lo necesario para cumplir con las funciones públicas encomendadas, sin acudir a las técnicas contractuales. En la doctrina, se reconoce que todos los supuestos de operaciones in house se justifican en:

"(...) la existencia de medios propios que permitan al poder adjudicador realizar las tareas de interés público que le corresponden sin recurrir a entidades externas, y ajenas a sus servicios. En definitiva, a un principio de eficacia o de buena administración que podría utilizarse para impedir contratos innecesarios" (Pernas García 19) ${ }^{(5)}$.

En efecto, si la administración ya cuenta con todo lo necesario para obtener el servicio o para llevar a cabo la obra por sus propios medios, ¿para qué contratarla con un tercero que, además de generarle un costo adicional, diferirá la decisión, al tener que seguir complejos procedimientos presupuestarios y selección para identificar a ese contratista?
En este sentido, la administración orienta su capacidad autoorganizativa persiguiendo mayores niveles de eficacia administrativa (Sosa, 1317) con la vía del aprovisionamiento directo de bienes, servicios y obras asumiendo dos criterios legitimadores validos: la capacidad preexistente de la administración para ejecutar satisfactoriamente la actividad y el ahorro de recursos que ello representa al no ingresar a obtener los bienes, servicios y obras del mercado, que agrega al costo la utilidad del empresario(6).

Precisamente, el requisito de la capacidad administrativa prexistente queda aludida en nuestra normativa cuando se exige -para proceder a realizar una obra pública por administración directa- que la entidad deba contar con "la asignación presupuestal correspondiente, el personal técnicoadministrativo y los equipos necesarios" y además que, en caso de requerir la colaboración de otra entidad pública, "los convenios que celebren las Entidades, para encargar la ejecución de obras por administración directa, deben precisar la capacidad operativa que dispone la Entidad Ejecutora a fin de asegurar el cumplimiento de las metas previstas" (R.C. No. 195-88-CG, artículo 1, numeral 1 y 2). Resulta evidente que, si una entidad contara ya con la infraestructura, el personal apto y especializado, materiales y la experiencia

(4) También se puede revisar del mismo autor: Juan José Pernas García, "La exigencia de control análogo en las encomiendas a medios propios", REALA Revista de Estudios de Administración Local y Autonómica 29 (Setiembre Diciembre): $229-276$ y 311 .

(5) Algunos de los estudios que explicitan los principales argumentos en favor de las operaciones de suministro doméstico de bienes y servicios son: (i) Francisco Sosa Wagner, "El empleo de recursos propios por las administraciones locales", en Estudios de derecho público económico: libro homenaje al Prof. Dr. D. Sebastián Martín-Retortillo, coordinado por Luis Cosculluela Montaner (2003), 1309-1342; (ii) Martín Rebollo Piug, "Los entes institucionales de la Junta de Andalucía y su utilización como medio propio", RAP 163: 245 y siguientes; y, (iii) A. Huergo, "La libertad de empresa y su colaboración preferente de las administraciones con empresas públicas", Revista de Administración Pública 129 (enero-abril 2000$)$ : 154.

(6) Las entidades también suelen aducir como factores de legitimación para esta acción, aspectos como, la celeridad de su formalización, la incapacidad del mercado para prestar los servicios requeridos, la mayor idoneidad de la entidad que los privados, lo estratégico de alguna actividad para transferirla a privados, pero ninguna per se justifica válidamente el uso de los medios propios, como veremos posteriormente. 
Las Obras por Administración Directa y por encargo ¿Solución o problema? ¿Hay que restringirlas? Proyects by direct management and custom proyects: solution or problem? Should we restrict them? adecuada para acometer la prestación, no solo resultaría recomendable sino necesario optar por la autoconstrucción $n^{(7)}$.

Por otro lado, el criterio legitimador del ahorro de recursos se incorpora cuando se exige que, para esta modalidad de ejecución, "la entidad debe demostrar que el costo total de la obra a ejecutarse por administración directa, resulta igual o menor al presupuesto base deducida la utilidad, situación que deberá reflejarse en la liquidación de la obra" (R.C. No. 195-88-CG, artículo 1, numeral 1 y 2).

El principal efecto de la administración directa es excluir de su ámbito -tanto en su formación como en su ejecución- a la regulación de los contratos administrativos para atender la necesidad al no existir ninguna relación bilateral de contenido patrimonial que le es inherente.

Dentro de este marco, la autoprovisión puede producirse bajo tres supuestos distintos ${ }^{(8)}$ :

a) La autoprovisión o administración directa en sentido estricto;

Que se produce cuando la realización del objeto de los contratos públicos son atendidos directamente por los servicios y dependencias de la misma entidad, esto es, con su propio personal, equipo, recursos presupuestales y gerenciales ubicados dentro de la misma organización administrativa, asumiendo por ende, la propia entidad, todos los riesgos inherente al proceso de aprovisionamiento. Aquí son los propios órganos de la entidad, sin personificación, quienes atienden las necesidades de su propia entidad.

Consideramos interesante diferenciar en el análisis, según la necesidad sea de bienes, servicios o de obras. En efecto, si la entidad necesita algún bien, no requiere obtenerlo de un proveedor externo si lo posee internamente, lo puede obtener transformándolo a partir de insumos que ya posee, repotenciando alguna anterior o si satisface su necesidad mediante transferencia patrimonial o afectación en uso de otra entidad pública (ejemplo, vehículos o inmuebles). En el caso de los servicios, igualmente si la entidad ya puede satisfacer sus necesidades de prestación de servicios de simple apoyo a la gestión (ejemplo: limpieza, mantenimiento, reparaciones, impresiones, transporte, limpieza) mediante reasignación de personal, organización de servicios o creación de un área especializada si lo justifique su demanda, no requerirá de proveerse por parte de proveedores externos. La decisión se torna un poco más compleja cuando se trata de la atender necesidades de servicios profesionales o técnicos (ejemplo, contabilidad, legales, jurídicos, clínicas, servicios médicos, informáticos, ingeniería), en los que según la frecuencia, especialidad o estrategia de gestión, la entidad adoptará la decisión de externalizarlos a proveedores o incluirse a personal adecuado en su plantel permanente para su atención por propios medios. Por su lado, cuando los servicios sean de complejidad profesional o de notoria especialización, ejemplo, capacitación en un software de última generación, patrocinio de un proceso arbitral complejo resulta más adecuado externalizarlo que asumirlo con sus medios propios. Finalmente, el caso de obras, se ejecutará por medios propios o por autoconstrucción cuando sean las propias dependencias o servicios de la entidad quienes la asumen porque ya poseen el personal calificado y con especialidades adecuadas al tipo de obra, con disponibilidad de tiempo y aptitud para planificar, organizar y gerenciar recursos, materiales y organizativos para hacer posible la ejecución de las actividades constructivas.

En ese sentido, desde la perspectiva presupuestaria, en todos estos casos nos encontramos en una ejecución financiera que la propia entidad realiza (LGSNP).

(7) En España, este requisito ha sido incorporado también mediante el Informe No. 65/07 del 29 de enero de 2009 de la Junta Consultiva de Contratación.

(8) Anteriormente, se previa como una posibilidad la administración directa en caso que se resolviera un contrato (Artículo 44 del Reglamento), lo cual ha sido omitido en la regulación actual. 
Juan Carlos Morón Urbina

b) La autoprovisión o administración directa en sentido amplio, mediante personas jurídicas estatales dependientes o instrumentales;

La autoprovisión también puede darse lugar cuando quien realiza la prestación no es un órgano o servicio al interior de la propia entidad, sino otra entidad pública diferente y con personificación propia, pero existiendo entre ella y la entidad aprovisionada una relación de subordinación. De este modo, también se reputa como administración directa cuando las actividades son acordadas por la entidad -a título de encargantecon otra entidad pública -de carácter instrumental-, que pese a contar con personería jurídica singular, mantiene una relación de dependencia o control con la entidad encargante, ejecutando a través de ambas, una sola voluntad organizativa de la administración. Así establecidos, "los encargos a medios propios se configuran como una relación de naturaleza instrumental, no contractual, de carácter interno, dependiente y subordinado, caracterizada por ser de ejecución obligatoria para las encomendatarias, con sujeción a las instrucciones fijadas unilateralmente por el encomendante y cuya retribución se fija (...) por la entidad pública de la que dependen"(9).

Como ejemplos de esta autoprovisión, mediante personas instrumentales podríamos señalar en nuestro país, los casos del Servicio Industrial de la Marina (SIMA) ${ }^{(10)}$ y la Fábrica de Armas y Municiones del Ejercito SAC (FAME SAC) con respecto a la Marina de Guerra del Perú(11), el Servicio de Mantenimiento del Perú SAC con la Fuerza Aérea del Perú(12), y el INVERMET con relación a la Municipalidad Metropolitana de $\operatorname{Lima}^{(13)}$.

En estos casos, aunque aparezcan formalmente dos entidades públicas en una relación convencional, no puede afirmarse que estamos ante un contrato propiamente dicho ${ }^{(14)}$, ya que la relación de dependencia de la ejecutora respecto

(9) Tribunal de Cuentas de España, Informe No. 1088, "Informe de fiscalización de las encomiendas de gestión de determinados Ministerios, organismos y otras entidades públicas llevadas a cabo al amparo de la legislación que habilita esta forma instrumental de gestión administrativa".

(10) Respecto del rol de SIMA con relación al aprovisionamiento a la Marina, es importante revisar el Informe No. 040-2001/GEE, "Evaluación de las condiciones para el desarrollo de actividad empresarial del Estado: Servicios Industriales de la Marina S.A. (Sima Perú S.A.)". Este informe revelaba que: (i) existían evidencias que la empresa realizaba actividades que exceden el ámbito de lo autorizado por ley, como obras civiles no complementarias ni conexas con la actividad metalmecánica del sector defensa (ejemplo, puentes, carreteras), reparación y mantenimiento industrial distinto a la defensa, consultorías para terceros; y, (ii) actuaba brindando servicios a terceros privados en los que había oferta privada real o potencialmente que la podía asumir (ejemplo, construcción de embarcaciones menores para particulares).

(11) Tanto el SIMA como FAMESA son empresas del Sector Defensa cuyos objetivos y estrategias son formuladas por el Ministerio. EI SIMA, conforme a su Ley 27073, "es una empresa estatal de derecho privado dentro del ámbito del Ministerio de Defensa (artículo 1), está sujeta a la supervisión de la Comandancia General de la Marina de Guerra del Perú, (artículo 2) y tiene por finalidad "efectuar en forma prioritaria la reparación, carena, alteración y construcción de los buques de la Marina de Guerra del Perú, así como los trabajos que esta le encargue con relación al mantenimiento de su equipamiento" (artículo 4).

(12) El Servicio de Mantenimiento del Perú SAC es una empresa estatal del sector Defensa, fabrica, mantiene, moderniza y repara aeronaves, motores, instrumentos, hélices, partes, accesorios y equipos de comunicaciones, calibraciones diversas y reparación de tarjetas electrónicas a la Fuerza Aérea del Perú.

(13) El Fondo Metropolitano de Inversiones - INVERMET es un organismo descentralizado de la Municipalidad Provincial de Lima Metropolitana con personalidad jurídica y autonomía administrativa, económica y técnica, que tiene por objeto proporcionar los recursos para el financiamiento y ejecución del Programa de inversiones y obras de la Municipalidad, y dentro de ese marco, recibe obras por encargo de la Municipalidad.

(14) Precisamente por ello afirma Gimeno Feliu que lo característico en este caso es la influencia dominante que ejerce el primero respecto del segundo, que determina una práctica dominación a la hora de determinación de las voluntades por lo que a lo sumo podría hablarse de un autocontrato. Véase José María Gimeno Feliu, "La problemática derivada del encargo de prestaciones a entes instrumentales propios: alcance de la jurisprudencia comunitaria", en Informe comunidades autónomas (2005): 838-55. 
Las Obras por Administración Directa y por encargo ¿Solución o problema? ¿Hay que restringirlas?

Proyects by direct management and custom proyects: solution or problem? Should we restrict them?

de la primera impide la existencia de un concurso espontaneo de voluntades, existiendo en puridad una sola voluntad decisora de esa instrumentación que la ordena, produciendo una prolongación funcional de la entidad aprovisionada mediante una "cooperación vertical o institucionalizada" (Tiago Ferreira 2015) entre ambas, que se exterioriza en un "encargo de gestión"(15)(16), que la más de las veces, son órdenes de ejecución obligatoria para el ente dependiente que consecuentemente no puede rechazar o condicionar en base a esa, falta de autónoma real (Bernal 2013, 104).

Cuando esto sucede, hablamos de los "convenios de encargo" entre entidades públicas y se encuentran excluidos del ámbito objetivo de la Ley de Contrataciones del Estado(17)(18).

Como esta forma de aprovisionamiento entre entidades estatales evita la aplicación del régimen de contrataciones ordinario, ha sido objeto de regulación específica que impida su tergiversación y lo concentre a los supuestos adecuados.

Así por ejemplo en Europa ${ }^{(19)}$, consolidando una amplia jurisprudencia del Tribunal de Justicia -producidas, fundamentalmente, al resolver cuestiones prejudiciales planteadas por Tribunales nacionales sobre aplicación de normativa de contratación pública a algunas operaciones- ha establecido(20) que para que la autoprovisión o administración directa en sentido amplio, mediante personas jurídicas estatales dependientes o instrumentales se procedente, es necesario la concurrencia de tres requisitos:

(15) Ley 27444, Ley del Procedimiento Administrativo General.Artículo 71.- Encargo de gestión

71.1 La realización de actividades con carácter material, técnico o de servicios de competencia de un órgano puede ser encargada a otros órganos o entidades por razones de eficacia, o cuando la encargada posea los medios idóneos para su desempeño por sí misma.

71.2 El encargo es formalizado mediante convenio, donde conste la expresa mención de la actividad o actividades a las que afecten el plazo de vigencia, la naturaleza y su alcance.

(16) Afirma correctamente Bernal Blay que en estos casos "nos encontramos ante supuestos en los que la Administración se sirve de un aparato instrumental para proveer obras públicas, suministros o para prestar servicios, de manera que la dependencia funcional que el proveedor o prestador presenta respecto de la administración debe llevarnos a entender que la relación que se establece entre ambos obedece, más que a una lógica contractual, a una decisión de tipo organizativo de la Administración. Debe entenderse por tanto que las sociedades públicas o cualesquiera otras formas de personificación son simples opciones de organización y el reconocimiento de una personalidad jurídica lo es solo a efectos instrumentales o auxiliares, pero que en modo alguno pueden ostentar la consideración de terceros respecto de esa misma administración". Véase: Miguel Ángel Bernal Blay, "Hacia una contratación pública local eficiente", en Convocatoria a Premios de Investigación (Zaragoza: Desarrollo Local, 2013), 103.

(17) Ley 30225, Ley de Contrataciones del Estado

"Articulo 5.- Supuestos excluidos del ámbito de aplicación sujetos a supervisión

c) Los convenios de colaboración u otros de naturaleza análoga, suscritos entre Entidades, siempre que se brinden los bienes, servicios u obras propios de la función que por ley les corresponda, y no se persigan fines de lucro".

(18) Mediante Opinión No. 028-2009/DTN del 30 de abril de 2009 sobre este tema se dejó establecido que: "se encuentran fuera del ámbito de aplicación de la Ley y de su Reglamento, los convenios de cooperación, gestión u otros análogos celebrados entre Entidades o entre estas y organismos internacionales, para que se brinden los bienes, servicios u obras propios de la función que por ley les corresponde, siempre que carezcan de finalidad lucrativa" (conclusión 3.2.) y que "si como consecuencia de la suscripción de un convenio de cooperación, gestión o análogo, una Entidad requiere llevar a cabo contrataciones de bienes y servicios para alcanzar la finalidad del convenio, tales contrataciones deberán realizarse observando las disposiciones de la Ley y su reglamento" (conclusión 3.4.).

(19) Directiva No. 2014/24/UE del Parlamento Europeo y del Consejo de fecha 26 de febrero de 2014 sobre contratación pública; Artículo 12, Contratos públicos entre entidades del sector público.

(20) Nos referimos a los conocidos "Criterios Teckal" o "Condiciones Teckal" establecidos desde la Sentencia Teckal del año 1999 (STJUE C/107/98 Teckal y ampliados/perfeccionados luego en posteriores sentencias). 


\section{Juan Carlos Morón Urbina}

b.1. Que la entidad aprovisionada ejerza sobre la persona jurídica proveedora un control análogo al que ejerce sobre sus propios servicios o dependencias o una influencia decisiva sobre objetivos estratégicos y decisiones significativas de la persona jurídica encargada;

b.2. Que la entidad instrumental realice la parte esencial de su actividad (más del $80 \%$ de las actividades) en favor de la entidad que la controla y recibe los bienes, servicios u obras, teniendo, por ende, únicamente un ámbito máximo de $20 \%$ que puede dedicar de su actividad a otras entidades o empresas, con lo cual se busca que la actividad prestacional con terceros no sea desarrollada como finalidad principal de esa entidad sino únicamente como accesorias; $y$,

b.3. Que no exista participación directa de capital privado en la persona jurídica controlada, con la excepción de las formas de participación de capital privado sin capacidad de control y que no ejerzan una influencia decisiva sobre la persona jurídica controlada.

En esta línea, cuando en una entidad concurren estos elementos se encuentra en aptitud para aprovisionar a la entidad encargante. Por el contrario, si no los cumpliera no podría hacerlo.

c) La auto provisión mediante convenios con otras entidades para prestar bienes, servicios y obra;

La tercera manifestación de la autoprovisión administrativa es la cooperación horizontal mediante la cual dos entidades sin mantener alguna relación de control o dependencia deciden autónomamente colaborar para alcanzar finalidades compartidas entre ambos. Nos encontramos dentro de un ámbito de la colaboración interadministrativa en un plano de igualdad entre entidades para la prosecución de tareas de interés común y público (Tiago Ferreira 2015).

Para ello, este convenio debe satisfacer las siguientes condiciones:

c.1. Que el contrato establezca o desarrolle una cooperación entre las entidades con la finalidad de garantizar que los servicios o funciones públicas que les incumben se prestan de modo que se logren los objetivos que tienen en común ${ }^{(21)}$;

c.2. Que el desarrollo de dicha cooperación se guíe únicamente por consideraciones relacionadas con el interés público;

c.3. Que los poderes adjudicadores participantes realicen en el mercado abierto menos del $20 \%$ de las actividades objeto de la cooperación;

c.4. Ausencia de fines de lucro, por lo cual no existe utilidad económica de la entidad colaborante; y,

c.5. Que la entidad encargada cuente en su finalidad u objeto social la capacidad para brindar los bienes, servicios u obras objeto de la cooperación ${ }^{(22)}$.

(21) Directiva 2014/24/UE del Parlamento Europeo y del Consejo de fecha 26 de febrero de 2014 sobre contratación pública; Artículo 12: Contratos públicos entre entidades del sector público.

(22) Véase Opinión No. 025-2014/DT de fecha 6 de febrero de 2014, donde se establecen los requisitos para los convenios de colaboración o cooperación entre entidades no dependientes. Dicho criterio se ha mantenido en diversos pronunciamientos: (i) Acuerdo celebrado entre Entidades, o entre Entidades y organismos internacionales: Una de las características distintivas de los convenios de cooperación, gestión u otros de naturaleza análoga, es que se celebran entre Entidades o entre Entidades y organismos internacionales.

(ii) Acuerdo sin fin de lucro: A través de la celebración del acuerdo, las partes no buscan obtener un beneficio económico (ganancia o utilidad) sino otro tipo de beneficios: cooperación mutua, gestión especializada, u otro fin de naturaleza análogo. En esa medida, la ausencia de beneficio económico se evidencia cuando la Entidad que recibe los bienes, servicios u obras no se encuentra obligada a pagarle una retribución a la otra Entidad u organismo internacional, según corresponda. Cabe precisar que, a partir de la celebración de un convenio de cooperación, gestión u otro de naturaleza análogo, puede generarse el compromiso de alguna de las partes de cubrir determinados costos o gastos administrativos, o de realizar 
Las Obras por Administración Directa y por encargo ¿Solución o problema? ¿Hay que restringirlas?

Proyects by direct management and custom proyects: solution or problem? Should we restrict them?
Nuevamente apreciamos aquí una forma de satisfacción de necesidades públicas atendidas sin acudir al mercado de proveedores, por cuando otra entidad puede realizarla sin cobro de lucro. Por ejemplo, las Universidades Estatales brindan a las entidades servicios técnicos de complejidad a través de sus docentes (por ejemplo, consultorías, capacitaciones, peritajes, investigaciones, etcétera).

\section{Las alternativas de las Municipalidades para ejecutar obras públicas}

Por el contrato de obra pública, la entidad encarga al contratista realizar, con su propia actividad, organización y medios, una o más prestaciones de ingeniería civil sujeta a ser medida por el resultado querido sobre inmuebles con sujeción a un proyecto o expediente previamente aprobado, por lo cual se obliga a pagar una retribución económica. Lo común es que el objeto del contrato sea la obra determinada concluida, ya que se busca un resultado específico y no una actividad o prestación, como en la locación de servicios. Como sabemos las prestaciones que pueden involucrarse en el contrato de obra son: las actividades construcción, reconstrucción, remodelación, mejoramiento, demolición, renovación, ampliación o habilitación de bienes inmuebles.

A su turno, los objetos que pueden ser materia de obra pública son inmuebles, tales como obras urbanas (edificios, colegios, hospitales, estadios), obras viales, obras portuarias, obras ferroviarias, obras penitenciarias, obras de trenes, obras aeroportuarias, obras portuarias, obras de saneamiento, obras electromecánicas, obras energéticas, obras de represamientos, obras de irrigaciones, obras de canalización, entre otras. Nótese que en todos los casos se trata de inmuebles y, ocasionalmente, bienes muebles por accesión a los primeros (como redes de ferrocarriles o carteles de señalización en una vía, que son accesorios a las obras ferroviarias o viables). Los objetos que están fuera del alcance de este contrato son la fabricación de bienes muebles (por ejemplo, vehículos) o bienes inmateriales (por ejemplo, planes).
Cuando las entidades necesitan la ejecución de una obra o construcción pueden acudir a cinco alternativas:

a) Por administración directa; en la cual es la propia entidad que con su personal, presupuesto y equipo acometen su ejecución.

b) Por el contrato de obra; por la que se encarga la ejecución a un contratista y venimos analizando.

c) Por medio de un contrato principal de organización (integrador) o de gerencia de proyecto de construcción; cuando se contrata a una empresa especializada en la gestión de dirección, administración y control del proyecto de construcción para que, asignándosele el presupuesto total de la obra, realice, bajo su propia responsabilidad, cuantos contratos sean necesarios para lograr el resultado, incluyendo a los ejecutores de la obra propiamente dicha, el supervisor, los proveedores, etcétera. Estará a cargo del gerente de construcción contratar, emplear y controlar los insumos de la obra, realizar los subcontratos y, en general, todo el proceso constructivo. Por lo general, su retribución puede verse expresada en una suma de dinero específica o en un porcentaje del costo general de la obra.

d) Por la concesión de obra; cuando dentro de un acuerdo de inversión privado se encarga la construcción a un privado para que recupere la inversión por medios de peaje u otros cobros a los usuarios.

contrataciones para alcanzar la finalidad del convenio, no obstante, ello no enerva la ausencia de un beneficio económico, pues dichos desembolsos no tienen la calidad de retribución o contraprestación.

(iii) Acuerdo celebrado para brindar los bienes, servicios u obras propios de la función que corresponde a la Entidad: El acuerdo se celebra para brindar los bienes, servicios u obras propios de la función que corresponde a las Entidades involucradas; por lo que no podrían ser materia de estos convenios, bienes, servicios u obras distintos a los antes indicados. 
Juan Carlos Morón Urbina

e) Por medio de las obras por impuestos; cuando la infraestructura es financiada por una empresa privada con cargo a los impuestos futuros que puede generar.

\section{La administración directa de obras públicas: aspectos controversiales}

La tendencia universal hacia el empleo no expansivo del autoprovisionamiento de bienes, servicios y obras por parte de las entidades proviene, fundamentalmente, de dos fuentes de críticas.

La primera es la óptica del mercado y de la libre competencia empresarial que aprecian en el empleo de medios propios serias implicancias negativas en la competencia en los mercados, pudiéndose resumir en tres defectos relevantes de esta práctica ${ }^{(23)}$ : a) porque detraen de la competencia porcentajes importantes de los gastos e inversiones públicas, lo cual significa, entre otras causas, que el efecto de las políticas fiscales no producen el resultado buscado a través del correspondiente (efecto) multiplicador; b) porque los servicios en ocasiones no se prestan con la calidad necesaria al estar encargados, en algunos casos, a empresas públicas sin los conocimientos ni las capacidades requeridas; y (...) c) porque dichas empresas subcontratan con frecuencia los trabajos que les son encargados sin que exista garantía de que lo hagan respetando las leyes de la competencia y cuidando la calidad y profesionalismo requeridas.

Complementariamente, pero no por ello menos importante, contamos con visiones críticas desde la visión de las instancias de control financiero del Estado(24), quienes mediante sus procesos de verificación atestiguan como estos medios conducen a situaciones de ineficacia, distintos a la proclamada eficiencia de la autorganización que la sustenta, además que al estar fuera del ámbito de la regulación contractual, no le resultan aplicables sus principios de publicidad, concurrencia, transparencia y no discriminación. Desde esta misma perspectiva, se atestigua la secuencia inconveniente de la apertura al servicio propio, luego la pretensión que este servicio se especialice y adquiera autonomía, posteriormente se le busca autosostenibilidad, permitiendo que brinde esas mismas actividades al sector privado, y finalmente demandando más recursos para proseguir in crecento sus actividades.

Con un objetivo pedagógico, a continuación expondremos los principales aspectos controversiales del autoprovisionamiento por medios propios.

\subsection{Compatibilidad con el mandato constitucional del artículo 76 de la Constitución Política del Estado}

Si comparamos los textos de los artículos constitucionales referido al deber de licitar los contratos públicos, a primera vista no apreciaremos cambios resaltables.

En efecto, mientras que la Carta de 1979 afirmaba lo siguiente:

(23) En este documento, se evalúa, como por ejemplo en España fueron creadas tres empresas instrumentales (TRAGSA, ISDEFE e INECO) para dar, en principio, estos servicios a otras entidades públicas en el ámbito de defensa, ingeniería, y agricultura. Las mismas que en su evolución asumen prestaciones para las cuales no están especializadas, con el objeto de mejorar sus ingresos, proceden a subcontratar con poca transparencia a terceras empresas gran parte de los servicios que necesitan proveer, y progresivamente aumentan el volumen de operaciones y personas dedicándose a actividades adicionales a las que justificaron su creación. Véase: Asociación Española de Empresa de Consultoría - AEC, El abuso en la utilización de las encomiendas de gestión (2012), 3.

(24) Ejemplo de esta preocupación lo podemos encontrar en el Informe No. 1088 del Tribunal de Cuentas de España aprobado, en su sesión de 30 de abril de 2015, titulado: "Informe de Fiscalización de las Encomiendas de Gestión de Determinados Ministerios, Organismos y otras Entidades Públicas llevadas a cabo al amparo de la Legislación que habilita esta forma instrumental de gestión administrativa". En dicho informe se muestran los resultados del análisis de las encomiendas de gestión formalizadas en los años 2011 y 2012 con entidades que tienen atribuida la condición de medio propio o servicio técnico y se muestran las conclusiones y recomendaciones relevantes. 
Las Obras por Administración Directa y por encargo ¿Solución o problema? ¿Hay que restringirlas?

Proyects by direct management and custom proyects: solution or problem? Should we restrict them?
Artículo 143.

La contratación con fondos públicos de obras y suministros así como la adquisición o enajenación de bienes se efectúan obligatoriamente por licitación pública. Hay concurso público para la contratación de servicios y proyectos cuya importancia y monto señala la ley de presupuesto. La ley establece el procedimiento, las excepciones y responsabilidades.

La Carta de 1993 parece ratificar esta disposición del modo siguiente:

\section{Artículo 76.-}

Las obras y la adquisición de suministros con utilización de fondos o recursos públicos se ejecutan obligatoriamente por contrato y licitación pública, así como también la adquisición o la enajenación de bienes.

Sin embargo, si lo vemos con detenimiento apreciaremos que mientras la primera refiere que cuando se realicen contrato con fondos públicos, con los objetos que se señalan, estos deben concretarse previamente con la licitación pública como procedimiento de conformación, la segunda Carta afirma, por el contrario, que las actividades constructivas y suministros que las entidades se necesiten, se ejecutan mediante contratos (contrata), lo cual supone dos notas propias: alteridad (dos personas contrapuestas en la relación contractual) y patrimonialidad de la relación jurídica entre estas partes. Lo que la norma constitucionalidad no solo está planteado la necesidad de realizar licitaciones públicas para formar contratos, sino que cuando las entidades necesiten de obras, adquisición de bienes y adquisición de suministros con utilización de fondos o recursos públicos, estos se deben adquirir obligatoriamente por contrata.

Aquí apreciamos un elemento nuevo que toma partido entre la polémica teoría entre el aprovisionamiento propio como primera opción y la del contratista interpuesto necesario para realizar construcciones o aprovisionamientos. Conforme a la primera tesis (no acogida por el legislador constituyente), el aprovisionamiento por medios propios sería siempre la preferente y prioritaria opción del gerente público, "de tal modo que solo en caso de que esa opción en sus distintas modalidades, no satisfaga en el caso concreto los criterios legales de racionalidad, eficiencia y buena administración, se podría acudir a la externalización contractual" (Amoedo, 3). Bajo el alcance de la Constitución vigente, ya no es posible afirmar que "la administración no está obligada a contratar nada que puede hacer ella misma mediante sus propios medios materiales y personales $y$, naturalmente, tiene el derecho de proveerse de esos medios propios para hacer por si misma cuando deba o pueda hacer" (Rebollo 2003, 379).

Por el contrario, el texto expreso de la actual carta indica que cuando las entidades necesitan suministros y obras los deben adquirir mediante contratos. De ese modo, la autoprovisión puede seguir existiendo, pero únicamente como excepción y sujeta a los procedimientos y condiciones que se establezcan para ello. Así tampoco, por imperio de esta regla constitucional, no será de aplicación a nuestro régimen lo afirmado por Rebollo Puig acerca de que "los empresarios privados no tienen ningún derecho a que la administración opte por no tener medios propios y por buscar su colaboración. Su derecho consiste en que si la administración decide buscar la colaboración de la empresa privada, lo haga de determinadas formas, garantizando en todo caso, la igualdad, publicidad y la concurrencia. Solo eso" (Rebollo 2003, 380).

4.2. La asunción total de los riesgos de construcción por parte de la administración Como sabemos, los contratos administrativos constituyen una forma de asignar y mitigar riesgos entre el contratante y el contratado para la ejecución de proyectos, como puede ser una construcción de obra. Una relación sencilla de estos riesgos la podemos exponer a continuación:

- Riesgos de diseño: errores en especificaciones técnicas, errores en el diseño entregado por el postor, equivocada supervisión del proyecto. 


\section{Juan Carlos Morón Urbina}

- Riesgos de construcción: variaciones de precios en la construcción por precio de materiales o equipamiento, riesgos geológicos, necesidad de partidas no previstas, demora en entrega de terrenos, falta de licencias o permisos administrativos, demora en aprobación de obras o pruebas, retraso en expropiaciones, demora en obtención de CIRAS, modificaciones pedidas por el Estado, defectos en ejecución de obra, hallazgo de restos arqueológicos.

- Riesgos Operacionales: variación de costos operativos complejidad de la operación, merma de niveles de eficiencia, mano de obra no calificada.

- Riesgos Económicos: derivados del comportamiento del mercado, tales como la fluctuación de los precios de los insumos, desabastecimiento y especulación de los mismos, entre otros.

- Riesgos Sociales: oposición de grupos sociales específicos (gremios, sindicatos, pobladores, etcétera).

- Riesgos Operacionales: operatividad del contrato (suficiencia del presupuesto oficial, del plazo o los derivados de procesos, procedimientos, parámetros, sistemas de información y tecnológicos, equipos humanos o técnicos inadecuados o insuficientes).

- Riesgos Financieros: son (i) el riesgo de obtención de financiación o riesgo de liquidez para obtener recursos y cumplir con el objeto del contrato; y, (ii) el riesgo de deterioro de las condiciones financieras establecidas para la obtención de los recursos, tales como plazos, tasas, garantías, contragarantías, y refinanciaciones, entre otros.

- Riesgos Regulatorios: cambios en las nomas o reglamentos que afecten el equilibrio económico del contrato, por ejemplo: tributos.

- Riesgos de la Naturaleza: son los eventos naturales previsibles que puedan tener impacto en la ejecución del contrato, (temblores, inundaciones, lluvias, sequías, incendio, sequias, desbordes, entre otros).

- Riesgos Ambientales: son los derivados de las obligaciones legales o reglamentarias de carácter ambiental, así como de las licencias, planes de manejo o de permisos y autorizaciones ambientales, obligaciones de mitigación, tareas de monitoreo y control de pasivos ambientales, entre otras.

- Riesgos Tecnológicos: son los derivados de suspensión de servicios públicos, nuevos desarrollos tecnológicos o estándares que deben ser tenidos en cuenta para la ejecución del contrato, obsolescencia tecnológica, exposición a cambios tecnológicos y demanda de reinversiones.

Pues bien, a diferencia de lo que sucede en el contrato administrativo, cuando la administración decide por la autoprovisión, está asumiendo integralmente a su cuenta la eventualidad de la ocurrencia de estos riesgos, sin la posibilidad de asignarlo o distribuirlo con la otra parte, que aquí no existe.

Por eso, se dice con razón que "(...) al decidirse por la administración directa, la entidad está asumiendo no solo los riesgos operativos de la ejecución de obra, sino también los de gerencia vinculados" (Mauricio 2014). A diferencia de los contratistas que cuentas con los incentivos adecuados para concluir la obra en plazo y forma para poder cobrar la utilidad y responder a sus acreedores (proveedores, trabajadores, financistas, accionistas, etcétera), los funcionarios públicos que están a cargo de la obra por encomienda se deben al principio de legalidad, al deber de seguir procedimientos reglados, sujetarse a autorizaciones previas, controles presupuestales, y otros, que complicada la gerencia del proceso constructivo.

Por ejemplo, si una entidad ejecuta un proceso constructivo con sus propios medios y se malogra la mezcladora de cemento, lo que corresponde es que el servidor a cabo del proceso debe solicitar la reparación, e iniciar un proceso logístico rutinario desde el estudio 
Las Obras por Administración Directa y por encargo ¿Solución o problema? ¿Hay que restringirlas?

Proyects by direct management and custom proyects: solution or problem? Should we restrict them? de mercado hasta la contratación del repuesto u obtener el servicio técnico para restituir la operatividad del equipo o determinar que deba ser sustituido. En ese mismo tiempo, la obra quedara probablemente paralizada afectado plazo y costos de personal, otros equipos, financieros (Mauricio 2014).

\subsection{El uso fraudulento para evadir el proceso de selección necesario y la subcontratación de terceros}

Una de las exigencias inherentes a esta operación, es que la administración cuente con los medios propios para asumir la tarea integralmente que no se externaliza. Por ello, aquí se exige que la entidad deba contar con "la asignación presupuestal correspondiente, el personal técnicoadministrativo y los equipos necesarios" y además que, en caso de requerir la colaboración de otra entidad pública, "los convenios que celebren las Entidades, para encargar la ejecución de obras por administración directa, deben precisar la capacidad operativa que dispone la Entidad Ejecutora a fin de asegurar el cumplimiento de las metas previstas".

Pareciera pretenderse que la entidad encargada debe asumir el íntegro de las prestaciones que realizara en favor de la otra, sin poder realizar la subcontratación de parte y menos todas las actividades encargadas. Sin embargo, ello no suele ser así, porque las entidades que califican como medio propio no solo no cuentan con los "medios necesarios" integralmente, sino que se ven en la necesidad de subcontratar parte de las actividades convirtiéndose en un mero intermediario entre la receptora final del bien, servicio u obra, y las empresas privadas que lo realizan efectivamente, incurriendo en "un fraude a la legislación de contratos públicos" (Chicano, 5), peor aún, como con frecuencia sucede, la encomendada emplea para contratar a terceros su régimen propio que suele ser más flexible que el de la entidad encargante.

Al respecto, un interesante estudio del Tribunal de Cuentas español(25) reveló que resultaba sumamente frecuente el recurso a la subcontratación por parte de los entes instrumentales para ejecutar algunas de las prestaciones objeto de los encargos encomendados, sin contarse con un límite legal para estas prácticas, de modo que los medios propios:
"Han podido actuar como meros intermediarios que habrían procedido a la contratación de determinadas prestaciones, en sustitución de su administración matriz, sin aplicar la legislación reguladora de la contratación pública con la misma extensión y rigurosidad que la prevista para las administraciones públicas, determinando con ello un cambio del régimen jurídico en materia de contratación pública, mucho más rápido y flexible en su tramitación, pero también con muchas menos garantías para el interés público"(26).

\subsection{La intervención en el mercado restringiendo la competencia}

Como es reconocido internacionalmente, la existencia misma de los medios propios va unida a la noción de restricción la competencia por la prestación de esos servicios a los actores privados, es por eso que:

"Cuando una Administración decide realizar una encomienda, el acceso a la prestación quedaría cerrado para todos los oferentes distintos del medio propio, limitando la capacidad de estos para ofertar sus productos o servicios, que en muchas ocasiones puede ser un importante demandante de los mismos. Por lo tanto, la decisión de satisfacer la demanda de aprovisionamiento mediante una encomienda de gestión elimina la posibilidad de celebrar una licitación pública y con ello la competencia en la provisión de la obra, bien o servicio en cuestión" (CNC 2013, 32).

De esta inherente limitación de acceso a terceros al mercado público producida por el empleo de medios propios, generalmente se

(25) Informe No. 1088 del Tribunal de Cuentas de España, "Informe de fiscalización de las encomiendas de gestión de determinados Ministerios, organismos y otras entidades públicas llevadas a cabo al amparo de la legislación que habilita esta forma instrumental de gestión administrativa", 132 y siguientes

(26) Informe No. 1088 del Tribunal de Cuentas de España, 135. 
Juan Carlos Morón Urbina

intensifica con su uso recurrente, con el empleo de encargos marco o convenios para varias prestaciones conjuntas o sucesivas, con lo cual se perpetua el cierre del mercado público en estos temas, impidiendo o desalentado la oferta privada que se podría formar o incrementar en estos rubros. Pero esta restricción a la competencia se manifiesta además cuando la entidad encargada se ve en la necesidad de subcontratar parte o todas las prestaciones para las cuales fue calificada como medio propio. En este supuesto, tampoco se produce un proceso abierto y competitivo para acceder al mercado estatal, procediéndose usualmente mediante mecanismos no públicos de contratación.

\subsection{Falta de transparencia en la concertación y ejecución} Otro de los aspectos controversiales de los encargos a medios propios es que, a diferencia de los contratos con proveedores, su formación y ejecución esta distante de la aplicación de las reglas de libre concurrencia, transparencia, igualdad y auditabilidad.

Resulta indiscutible que en estos encargos existe un déficit de transparencia que impide saber a ciencia cierta porqué fue elegido el medio propio, cómo se establecieron sus condiciones para el aprovisionamiento (plazos, calificaciones, precios, equipos, etcétera). Este proceso está alejado del control ciudadano o de los posibles postores sobre el verdadero cumplimiento de las condiciones para la concreción de la obra por administración directa, como si ocurre en los concursos públicos sujetos al control sucesivo vía recursos administrativos. Aun en la fase posterior de ejecución, no existe accesibilidad a los ciudadanos sobre las fases del proceso de formación del encargo, como si acontece con los contratos sujetos a régimen de competencia.

Del mismo modo, en las entidades encargadas no existe un régimen de separación de presupuestos, recursos y de patrimonios a dedicarse a cumplir el encargo con respecto a los presupuestos, recursos y patrimonios de la misma entidad que no está afectos a la realización del encargo. Surgiendo de eso una confusión de patrimonios sin posibilidad de poder llevar un control de costos y avances.

Por el lado de la entidad encargante, dentro del diseño del encargo, carece de los instrumentos comunes de los contratos estatales para controlar el cumplimiento en tiempo y forma de las prestaciones (por ejemplo, supervisor, penalidades, calendarios, cuaderno de obra, entre otros). Produciéndose entonces una sustitución de la legalidad, tecnicismo y debate intersubjetivo propio de la alteridad proveedor/contratista con la cual se deben tomar las decisiones de control de la ejecución contractual, por las decisiones políticas y discrecionales propias de un ámbito en el que una de las partes tiene control respecto a la otra, le fija las condiciones unilateralmente, teniendo además el factor adverso que "la continuidad y cercanía en la relación con el medio propio, cuyo control ostenta, puede reducir el nivel de exigencia" (CNC 2013, 44).

\subsection{La distorsión en la formación del precio: ausencia de un precio suficiente}

La determinación de la formación del precio con que se retribuida al organismo a cargo de la prestación dista de ser formado en el mercado y más bien, posee una serie de condiciones que tienden a distorsionarlo(27). Evidentemente, para mantenerse en el ámbito de las relaciones de autoabastecimiento y cooperación, el precio de la autoprovisión debe evitar "márgenes de rentabilidad que no entran dentro de la lógica y la coherencia jurídico-económica de la encomienda de gestión, ya que las entidades encomendatarias se financian con fondos públicos, con lo que

(27) Para un análisis del aspecto de la formación de precios en la autoprovisión por medios propios puede revisarse: (i) Mario Garcés Sanagustín. "La auto contratación o contratación 'in house providing'. Incidencia de la nueva regulación en las entidades instrumentales del sector público. Concepto de instrumentalidad y régimen tarifario". Gobierno de La Rioja; y, (ii) Ana Cossio Capdevila. 2013. "La fiscalización de la encomienda de gestión como forma de autoorganizacion administrativa: poniendo límites a la huida del derecho administrativo en materia de contratación pública”. Revista Auditoría Pública 61. 
Las Obras por Administración Directa y por encargo ¿Solución o problema? ¿Hay que restringirlas?

Proyects by direct management and custom proyects: solution or problem? Should we restrict them? no asumen riesgo del empresario particular, y actúan en las relaciones con su matriz como si de un órgano técnico jurídico se tratase" (Chicano, 4). Más aún, si las encomendatarias percibieran márgenes de rentabilidad por estas operaciones, estaría realizando una actividad empresarial y por ende, perturbando la competencia con las empresas privadas.

Lo que sucede, como regla general, es que el precio sujeto a esta restricción resulta insuficiente ab initio, porque "la retribución de las encomiendas de gestión se realiza mediante tarifas fijadas por la entidad administrativa de la que depende la entidad encomendataria" (Chicano, 4) con poco o nula capacidad de contrapropuesta del medio propio, precisamente porque se encuentra en relación de subordinación controlada por la primera. Ello conducirá a la existencia de ineficiencias en la evolución de la retribución en la fase de ejecución de la obra o, en otros, de sobrecompensación para buscar retornar al equilibrio necesario inicial o a cubrir los costos de los subcontratistas que trataran de ejecutar la prestación. No tenemos noticia de algún estudio concreto que determine si los precios convenidos originalmente por las actividades guarden correspondencia efectiva con los precios finales y costos de las actividades realizadas (CNC 2013).

\section{Conclusiones}

- Constitucionalmente, las operaciones de auto organización de las entidades para aprovisionarse de bienes, servicios y obras son supuestos excepcionales que únicamente proceden cuando se dan los supuestos considerados para ello por la normativa.

- Existen tres supuestos de auto aprovisionamiento: (i) la provisión interna de bienes, servicios y obras (autoconstrucción); (ii) la provisión con organismos instrumentales por medio de encargos; y, (iii) los convenios de cooperación en los que ambas partes colaboran para una finalidad pública pero sin involucrar utilidad para la encargada.

- Las dos condiciones que justifican las operaciones internas de este tipo son la prexistencia de medios propios en cantidad, calidad y disponibilidad, así como el ahorro de recursos que implican los acuerdos sin lucro que deben ser más económicos que acudir al mercado.
- La administración directa de obras públicas tiene condiciones negativas para la eficacia de la gestión que deben evitarse: (i) la asunción integra de los riesgos de la construcción por parte de la administración; (ii) El uso fraudulento para evadir el proceso de selección necesario; (iii) la restricción al acceso y crecimiento del mercado de proveedores, (iv) la falta de transparencia en la concertación y ejecución de la administración directa; y, (v) La distorsión en la formación del precio que impide contar con un precio suficiente desde el inicio y su contención posterior.

- Algunos aspectos que la legislación debería considerar sobre este tema son: la habilitación para la realización de obras menores y de complejidad básica, como remodelaciones, habilitación, demoliciones y en caso de ausencia de postores, restringir la posibilidad de subcontratar prestaciones, establecer mecanismos de publicidad de los acuerdos por encargo, prever la posibilidad de impugnación de los encargos por postores potenciales, un control permanente para verificar que en su ejecución se han cumplido las condiciones de eficacia que se adujeron para su celebración.

\section{Referencias Bibliográficas}

Amoedo Souto, Carlos. La auto provisión administrativa como alternativa a la externalización contractual de servicios. Comunicación presentada al "XXI Congreso Ítalo-español de profesores de Derecho Administrativo".

Bernal Blay, Miguel Ángel. 2013. "Hacia una contratación pública local eficiente", en Convocatoria a Premios de Investigación, 103. Zaragoza: Desarrollo Local. 


\section{Juan Carlos Morón Urbina}

Comisión Nacional de la Competencia (CNC). 2013. Los medios propios y las encomiendas de gestión: implicaciones de su uso desde la óptica de la promoción de la competencia, 32. https:// www.cnmc.es/Portals/0/Ficheros/Promocion/ Informes_y_Estudios_Sectoriales/2013/ CNC_MEDIOS $\% 20$ PROPIOS $\% 20 Y \% 20$ ENCOMIENDAS_rev.pdf

Chicano Javega, Enriqueta. El control de los contratos in house: análisis de las principales áreas de riesgo. Tribunal de Cuentas de España, 5.

De La Quadra Salcedo, Tomas."Ejecución de obras por la administración", en Comentarios a la Ley de Contratos de las Administraciones Publicas, coord. Rafael Gómez-Ferrer Morant. 2a ed. Thomson, 892.

Huergo, A. "La libertad de empresa y su colaboración preferente de las administraciones con empresas públicas". Revista de Administración Pública 129 (eneroabril 2000): 159.
Mauricio, Frank. 2014. Administración directa o la decisión de 'hacer-comprar' en la logística de las obras públicas.

http://www.esan.edu.pe/conexion/actualidad/2014/04/17/ administracion-directa-decision-hacer-comprar-logisticaobras-publicas/

Pernas García, Juan José. "Las operaciones in house y el derecho comunitario de contratos públicos. Análisis de la jurisprudencia dl TJCE". Iustel, Colección Practica y Jurisprudencia Administrativa 4, 176.

Rebollo Piug, Manuel. 2003. Los entes institucionales de la Junta de Andalucía y su utilización como medio propio. Revista Administrativa Pública 161 (mayo-agosto): 245 y siguientes.

Sosa Wagner, Francisco. 2003. "El empleo de recursos propios por las administraciones locales”. En Estudios de derecho público económico: libro homenaje al Prof. Dr. Sebastián Martín-Retortillo, coord. Luis Cosculluela Montaner, 1309-42.

Tiago Ferreira, Durval. 2015. "El régimen de la contratación in house según las nuevas directivas de contratación pública" pública". Contratación administrativa práctica: revista de la contratación administrativa y de los contratistas 139: 52-60. 